\title{
THE IMPACT FACTOR OF COSTS TO THE TAX SYSTEM
}

\author{
Constantinos Challoumis \\ National and Kapodistrian University of Athens, Greece \\ E-mail: challoumis_constantinos@yahoo.com \\ Received August 2019; accepted December 2019
}

\begin{abstract}
This paper is about the costs of the enterprises to the tax system. Thence, we have an analysis of the impact factor of the tax revenues of the countries subject to the costs of companies on the tax system. Thereupon from the view of the level of influence of the enterprises which participate in controlled transactions of transfer pricing to the global tax revenue, it is plausible to identify the impact factor of costs, when there exists that factor with the case which that factor is avoided. The impact factor of costs in combination with the tax revenues is determined through the Q.E. method and the R.B.Q. model. Inasmuch as, is defined as the behavior of the tax system subject to the capital of the tax system. Then a quantitative simulation is used as a methodology for this work, to define the impact of costs on the enterprises.
\end{abstract}

\section{Research paper}

Keywords: Transfer pricing; Costs; Tax revenue; Transactions

Reference to this paper should be made as follows: Challoumis, C. (2020). The Impact Factor of Costs to the Tax System, Journal of Entrepreneurship, Business and Economics, 8(1), 1-14. 


\section{Introduction}

This paper shows applying a quantitative simulation that the companies that increase their costs, of course, having more expenses seems that the companies are losing money, but as the final result will be to have much more income (OECD, 1991, 1999, 2000, 2017). On the other hand, from the simulation showed that the global tax revenue is decreased when the companies have lower costs. So, we have a contradiction, between the global tax revenue and the costs of companies (Kuhn, 1962; Salamzadeh et al., 2017; Batrancea et al., 2019). Then, the conclusion is that temporarily the increasing costs decrease the money deposit of the companies, but finally the will have much more profits (Boland, 1991; Rein and Schon, 1993; Hallerberg and Bassinger, 1998; Ariely et al., 2003; Khajeheian et al., 2018; Salamzadeh, 2018; Emami and Khajeheian, 2019). Contemporaneously, the tax authorities should try to reduce the costs of the companies or to make it cheaper, to achieve more tax income for the tax revenue (King, 1984; Hoynes, 1996; Camerer, 2003). These findings are unique as similar research with this method is limited.

The structure of the paper has the following sections: Applied methodology to the theoretical background, Impact factor of tax revenues, Determination of costs of the tax system, Impact factor of costs to the revenues of the tax system, and to the final section are the conclusions. 


\section{Research methodology}

The cycle of money is a theory based on the idea that the public and tax authorities should boost small or medium enterprises with lower taxes and from the bigger companies to retain low taxes only for production units e.g. factories, etc. (Argyris and Schon, 1974; Gordon, 1976; Habermas, 1968; Wilson, 1986). The bigger companies which overlap smaller companies make weaker the economy as the money that they receive doesn't return back to society (Meier and Rosenbaum, 2000; Doshmanli et al., 2018). The sense of escape savings is about the money which leak from an economy and doesn't return back for consumption, investments, and reinvestments. This paper is about the ideal case of the cycle of money and its normal form. The quantification analysis of the costs of the tax system with the tax revenue from a global view is done by the application of the Q.E. method (Challoumis, 2017, 2018, 2019). On that ground of this method is determined the behavior analysis of mathematical equations. Thence, there we clarify two levels to the analysis of the Q.E. method which are those:

- The analysis of the behavior of the model which stands on the scrutiny of the structural characteristics of each model accordingly allowing with that way the extraction of general conclusions about the model which is under examination.

- The frequency analysis behavior scrutinizes the behavior of the dependent variables, but from the view of the number of appearances of a variable than another, estimating basically the impact that one 
independent variable has with one or more other independent variables.

Thereupon, using the previous two axes of the Q.E. method is plausible to extract conclusions about the behavior of mathematical equations and the way that some factors react to changes. Consequently, is plausible the transformation of quality data to quantity data. This method is applied for the purposes of this study for controlled transactions and more precisely in the variables of the impact factor of the tax revenue. The mechanism of Q.E. is based on the dependent variables which are modified for the generator. Thereupon, the generator produces values for the dependent variables. The extracted values of the generator permit the creation of magnitudes, which are the base for comparisons, and for the scrutiny of mathematical equations. Thus, is plausible to quantify qualitative data. In our analysis, this method is used for the purposes of clarification of the behavior of the impact factor of the global tax revenue.

\section{Impact factor of tax revenues}

The impact factor of tax revenues of countries which are tax heaves, $s$ according to the "Methods of controlled transactions and identifications of tax avoidance" 1 is determined as that ${ }^{2}$ :

1 Challoumis, Constantinos, Methods of Controlled Transactions and Identification of Tax Avoidance (February 4, 2018). Available at SSRN: https://ssrn.com/abstract=3134109.

${ }^{2}$ Caution: The section I and the section II are the same for five papers, because are the base for the analysis of each factor of equation (1). Then sections I, and II are the preliminary requirements for the the analysis of each factor by separate papers. 
$s=\frac{k+l}{r+c+t+i}$

Therefore, are countries that receive products are taxed in different countries. This allocation of profits between profits and losses permits the enterprises which participate in controlled transactions of the transfer pricing activities to maximize their utility. But, contemporaneously the tax revenue from global view is declined. Then, the loss of tax income from some countries is more than the profits that make the countries which are tax heavens. Thereupon, the symbol of $s$ the impact factor of tax revenue from a global view, and there are some coefficients which are $k, l, r, t, \mathrm{i}$ and $c$. Thus, the symbol of $k$ is about the impact factor of capital, $l$ is the impact factor about the liability of the authorities on the tax system. The interpretation of the liability is about how much unbalanced it is the tax system. The parameter of $r$ is about the risk; the $t$ is about how much trustworthy is the tax system (bureaucracy). The symbol of $i$ examines the case of intangibles (the intangibles which charged to the subsidiaries) of the tax system (Goodman, 1978; Gomes-Casseres, 1989). Additionally, the symbol of c is about the cost of enterprises. The symbols with the " " are accordingly the same thing but from the view of the uncontrolled transactions ${ }^{3}$. Thus, the numerator is proportional to the income of taxes, as the investments and the stable tax environments, with liability, enhance the tax income. On the other hand, the denominator is inverted proportional to the tax income, as the risk,

\footnotetext{
${ }^{3}$ Uncontrolled transactions are the transactions which happen between companies free of control and allocation of profits and losses. 
the cost, and the unbalance of taxation cause less tax income. Moreover, for $\tilde{s}$ we have that:

$$
\tilde{S}=\frac{\tilde{k}+\tilde{l}}{\tilde{r}+\tilde{c}+\tilde{t}+\tilde{l}}
$$

In as much as an equation, the equation (3) is determined the aggregate impact factor of tax revenues, which is symbolized by $\hat{s}$, and is defined by the next equation:

$$
\hat{s}=s+\tilde{s}
$$

Based on the prior equations, we could proceed to the identification of the behavior of the impact factors of tax revenues in the case tax heavens and in the case of the non-tax heavens. Consequently, using the prior equations is plausible to examine the controlled and uncontrolled transactions. Then, $s$ is a factor that allows the comparison between the controlled with the uncontrolled transactions. Thence is able to have a standalone behavior analysis of controlled transactions and a combined behavior analysis between the controlled transactions with the uncontrolled transactions. In the next section is analyzed the impact factor of tax revenues with the rest impact factors.

\section{Determination of costs of the tax system}

The determination of costs of the tax system is established by the impact factor of costs which shows the level of influence of costs in the business plan of the enterprises. To clarify the way that costs affect the global tax revenues, we proceed with the following diversion: 
- The first application of Q.E. methodology is applied to all the factors of the global tax revenue, $s$. In that case, is plausible to obtain the behavior of the global tax revenue using the completed form of the equation (1).

- In the second application of Q.E. methodology is applied all the factors except the factor which is under review. Thereupon, in that case, is avoided the factor of costs of the tax system, $s$.

This methodology is illustrated below:

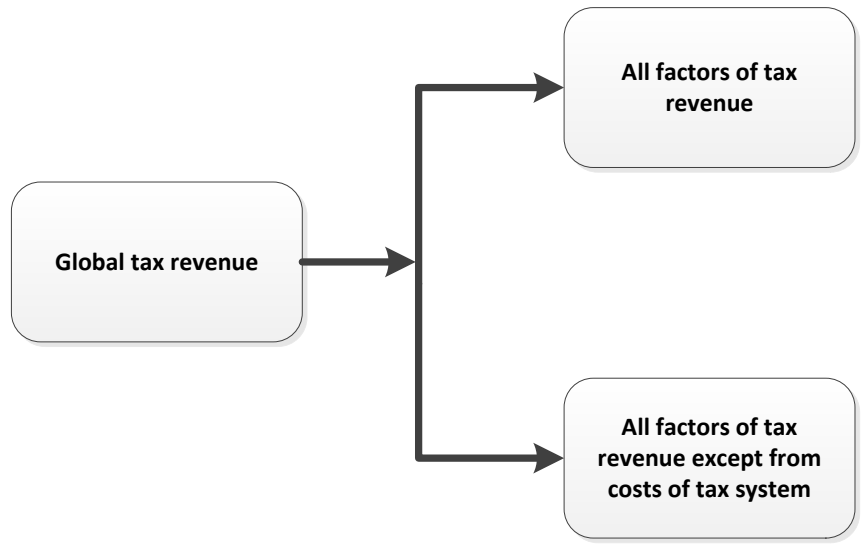

Figure 1. Steps of Q.E. application

The previous scheme is shown the methodology followed by the Q.E. method to determine the behavior of the global tax revenue in the case that there exist the costs in the controlled transactions of the transfer pricing and the case that we have an absence of the impact factor of costs. 


\section{Impact factor of costs to the revenues of the tax system}

The costs of the tax system are in interaction with the impact factor of tax revenues. In this behavioral analysis is determined the model which explains the behavior of the impact factor of tax revenues with the existence and with avoidance of the impact factor of costs. All the necessary equations have referred to in the previous sections, except from one condition. Then, for the application of the Q.E. method, we use the following condition, which is:

$t>l>i>r>k>c$

Therefore, is plausible to proceed to a quantitative analysis using equations (1), (2), and (4). The examination of tangibles with the costs is critical for the transfer pricing theory. The examination of capital is used many times from the enterprises of controlled transactions to reach the arm's length principle. ${ }^{4}$ Thence, applying the Q.E. method and choosing the appropriate values for the coefficients of global tax revenue, we have that:

\begin{tabular}{ccc}
\hline Factors & Values of $\mathbf{s}$ & Values of s' \\
\hline $\mathrm{k}$ & 0,4 & - \\
$\mathrm{i}$ & 0.6 & 0.6 \\
1 & 0.7 & 0.7 \\
$\mathrm{r}$ & 0.5 & 0.5 \\
$\mathrm{c}$ & 0.3 & 0.3 \\
$\mathrm{t}$ & 0.8 & 0.8 \\
$\mathrm{fs}$ & $<0.3$ & $<0.3$ \\
$\mathrm{fs}_{\mathrm{i}}$ & $<0.3$ & $<0.3$ \\
\hline Table1. Compiling coefficients
\end{tabular}

\footnotetext{
${ }^{4}$ As arm's length principle is determined the compliance between controlled transactions with the uncontrolled transactions. The arm's length principle is used as index that companies of controlled transactions comply with the tax requirements of the tax authorities.
} 
Thereupon, using the previous factors is able to determine the behavior of the model through the generator of the Q.E. method. The factors of the prior table have as an upper limit the 1 and as a lower limit the 0 . But, $s$ and $\tilde{S}$ are plausible to receive values greater than one as their mathematical structure allows this. After 461 iterations extracted the next diagrams:

(a)

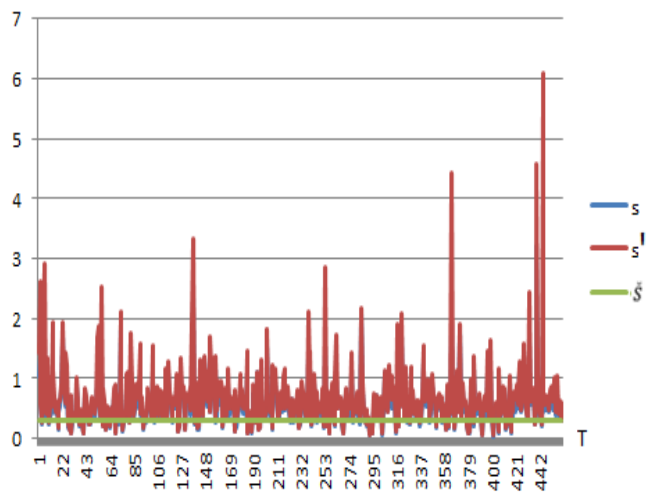

(b)

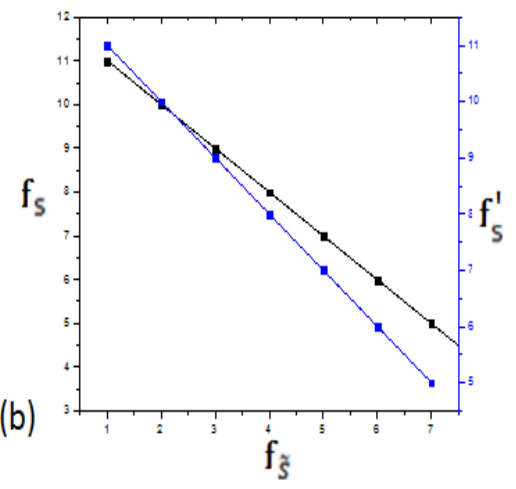

Figure 2. (a) Impact factors of $s$ (series 1) and $s^{\prime}$ (series 2), (b) frequencies of $s$ and $s^{\prime}$ (see Appendix)

In the prior figure, we used the $\tilde{s}$, which here is the same for the case that we have the costs and in the case that we have avoided costs. Then with $s$ (blue line) is symbolized the case that we have the impact factor of $c$ which symbolizes the costs which have the enterprises in the environment of the tax system. With $s^{\prime}$ (red line) is symbolized the case that we have avoided the costs, $c$. The global tax revenue is higher in the case that we don't have the costs (red line) than in the case that the impact factor of costs exists (blue line). As we expected the absence of costs increases the global tax revenues. The reason for the diminished global tax revenues in the case of $s$ is because the costs make the companies of controlled transactions to reduce 
their activities. Should be mentioned that for the purpose of the comparative analysis we used $\tilde{s}$ as constant to be able to compare $s$ with $s^{\prime}$. Additionally, from the diagram (b) of figure 2, we obtain that the frequency of the $f_{s}$ (black line) is higher than the frequency of $f_{s}{ }^{\prime}$ (blue line). Therefrom, the enterprises which participate in controlled transactions of transfer pricing with costs are more than in the case that we do not have costs [blue line of diagram (b)]. The interpretation of this economic situation is that the costs make the enterprises to increase their business activities. As cost is not considered the tax obligations, but the investments of companies for the enforcement of their commercial activities.

\section{Conclusions}

Then, the costs increase the spending of the companies, but this comes back as feedback to the profits of the companies. This means companies that don't spend they will not have to extend profits. Also, the same time the global tax revenue increased when the capital is increased. The increasing costs for the scopes of the business activities of companies help them to grow. Simultaneously the low costs increase the global tax revenue from the increase of entrepreneurs' activity. This situation shows that the tax authorities should try to reduce the costs for the companies, and at the same time, the companies should try to enlarge their activities through more spending which will come back from the market profits. 


\section{Appendix}

The sample code on Matlab for the model of costs to the tax system:

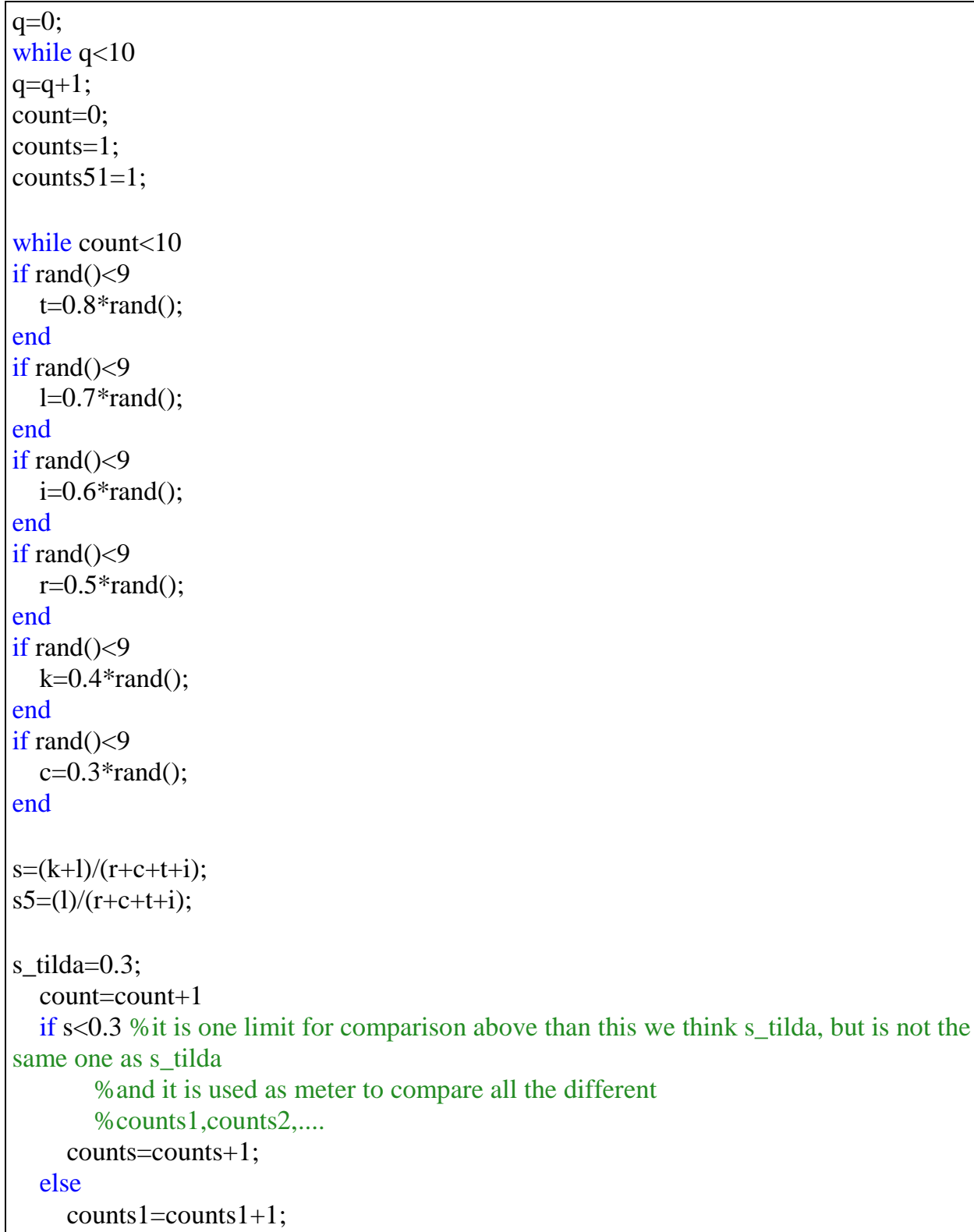




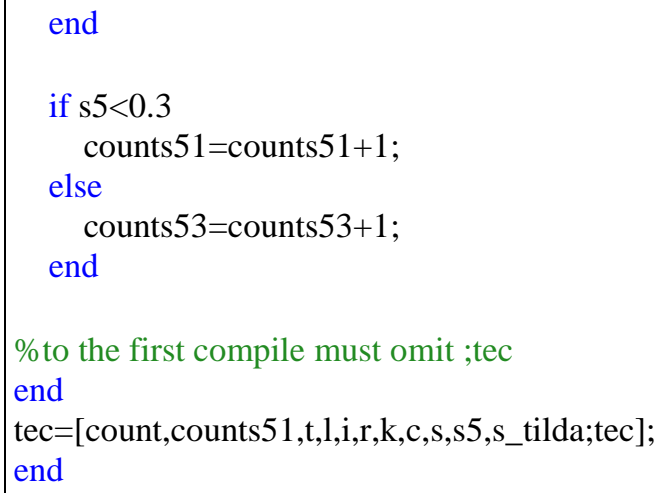

\section{References}

1. Argyris, C., Schon, D. A. (1974). Theory in Practice. San Francisco: Jossey-Bass.

2. Ariely, D., Loewenstein, G., \& Prelee D. (2003). Coherent arbitrariness: Stable demand curves without stable preferences. Quarterly Journal of Economics, 118, 73-105.

3. Batrancea, L., Nichita, A., Olsen, J., Kogler, C., Kirchler, E., Hoelzl, E., ... \& Schaffner, M. (2019). Trust and power as determinants of tax compliance across 44 nations. Journal of Economic Psychology, 74, 102191.

4. Boland, Lawrence A. (1991). The Methodology of Economic Model Building. London and New York: Routledge.

5. Camerer, C. F. (2003). The behavioral challenge to economics: Understanding normal people. Federal Reserve of Boston meeting "How Humans Behave", Caltech, Pasadena CA 91125, 134.

6. Challoumis, C. (2019), The arm's length principle and the fixed length principle economic analysis, World Scientific News, 115, pp.1-12

7. Challoumis, C. (2017). Quantification of Everything (a Methodology for Quantification of Quality Data with Application and to Social and Theoretical Sciences) Available at SSRN: https://ssrn.com/abstract=3136014

8. Challoumis, C. (2018). Identification of significant economic risks to the international controlled transactions. Annals of Dunarea de Jos, University of Galati Fascicle I. Economics and Applied Informatics, 3, 1-5. 
9. Challoumis, C. (2018). Methods of Controlled Transactions and the Behavior of Companies According to the Public and Tax Policy, Economics, 6(1), 33-43.

10. Challoumis, C. (2018). The impact factor of health on the economy using the cycle of money, Bulletin of the Transilvania University of Brasov, 2, 1-4.

11. Challoumis, C. (2018). The Role of Risk to International Controlled Transactions. Annals of Dunarea de Jos, University of Galati Fascicle I. Economics and Applied Informatics, 3, 2-5.

12. Challoumis, C. (2019). The R.B.Q. (Rational, Behavioral and Quantified) Model, Ekonomika, 98(1), 6-18.

13. Doshmanli, M., Salamzadeh, Y., \& Salamzadeh, A. (2018). Development of SMEs in an emerging economy: does corporate social responsibility matter? International Journal of Management and Enterprise Development, 17(2), 168-191.

14. Emami, A., \& Khajeheian, D. (2019). Social Norms and Entrepreneurial Action: The Mediating Role of Opportunity Confidence. Sustainability, 11(1), 158-172.

15. Gomes-Casseres, B (1989). Ownership Structures of Foreign Subsidiaries: Theory and Evidence, Journal of Economic Behavior and Organization 11, 1-25.

16. Goodman N. (1978). Ways of Worldmaking. Indianapolis: Hackett.

17. Gordon L .V. (1976). Survey of Interpersonal Values- Revised Manual, Chicago: Science Research Associates.

18. Habermas, J. (1968). Knowledge and Human Interests. Boston: Beacon Press.

19. Hallerberg M., S. Bassinger (1998). Internationalization and changes in tax policy in OECD countries: the importance of domestic veto players, Comparative Political Studies, 31, 321-353.

20. Hoynes, H. W. (1996). Welfare transfers in two-parent families: Labor supply and welfare participation under AFDC-UP. Econometrica, 64(2), 295-332.

21. Khajeheian, D., Friedrichsen, M., \& Mödinger, W. (Eds.). (2018). Competitiveness in Emerging Markets. Springer International Publishing.

22. King, M.A., D. Fullerton (1984). The Taxation of Income from Capital The University of Chicago Press, Chicago

23. Kuhn, T. (1962). The Structure of Scientific Revolutions. Chicago: University of Chicago Press.

24. Meier B. D., \& Rosenbaum D. T. (2000). Making single mothers work: Recent tax and welfare policy and its effects. National Tax Journal, 53(4), 1027-1061.

25. OECD (1991). Taxing Profits in a Global Economy OECD, Paris.

26. OECD (1999). The OECD Database for Industrial Analysis. OECD, Paris. 
27. OECD (2000). Towards Global Tax Cooperation. Report to the 2000 Ministerial Council Meeting and Recommendations by the Committee on Fiscal Affairs. OECD, Paris.

28. OECD (2017). Transfer Pricing Guidelines for Multinational Enterprises and Tax Administrations, OECD Publishing, Paris.

29. Rein, M., Schon, D. (1993). Reframing policy discourse in F. Fischer, John Forester. The argumentative turn in policy analysis and planning. UCL Press, 146-166.

30. Salamzadeh, A. (2018). Start-up Boom in an Emerging Market: A Niche Market Approach. In Competitiveness in Emerging Markets (pp. 233-243). Springer, Cham.

31. Salamzadeh, A., Arasti, Z., \& Elyasi, G. M. (2017). Creation of ICT-based social start-ups in Iran: A multiple case study. Journal of enterprising culture, 25(01), 97-122.

32. Wilson J.D. (1986). A theory of interregional tax competition Journal of Urban Economics, 19(3), 296-315. 